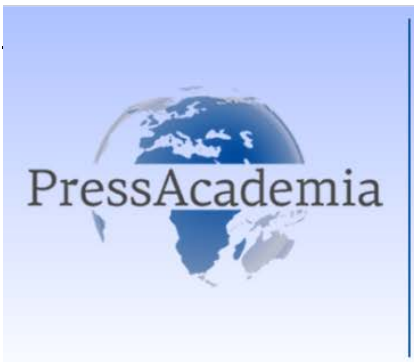

Press Academia Procedía

Global Business Research Congress (GBRC), June 4-5, 2015, Istanbul, Turkey.

\title{
THE EVELOTION OF LIFTING AND MOVING WITH VACUMING SYSTEMS EFFECTS ON PUBLIC HEALTH
}

\section{DOI: 10.17261/Pressacademia.2016118136}

\author{
Hale Alici ${ }^{1}$, Tulin Gunduz ${ }^{2}$ \\ ${ }^{1}$ Işık Üniversitesi. hale.alici@isikun.edu.tr \\ ²Uludağ Üniversitesi. tg@uludag.edu.tr
}

\begin{abstract}
Workers are applying momentum and power which different duration and time in their working area. There are differences between workers, cause ofsex, age, health status, experience, disabling. Also settling of works effects the limits of power and momentum which applied. There are a lot of different accounting method which obtained reserch and experience to determine power and momentum applied by workers. In this study it was analaysed weight on workers who works in lift and movement job with vacuming systems. Rubber goods between 9 and $25 \mathrm{~kg}$ weight were moved from container to conveyor in this study. 150 pcs rubber good which is different weight and size has moved every day by a worker who employed on this job. Analaysis by REBA method and ergonomic risk evalaution has done depend on Assessment Methods of Occupational Safety and Occupational Medicine Institutions of Germany. By the studies has contributed to reducing the disease ofmusculoskeletal system in the health management.
\end{abstract}

Keywords : Healthcare management, ergonomics, assessment methods of occupational safety and occupational medicine Institutions of Germany, REBA method.

JEL Codes: I10, L62

\section{VAKUMLU SISTEMLER ILE YÜK KALDIRMA VE TAŞIMA IŞININ INSAN SAĞLIĞINA ETKISININ DEĞERLENDIRILMESi}

\section{ÖZET}

Çalışanlar iş yerlerinde süreleri ve büyüklükleri farklı olarak kuvvet ve moment uygulamak zorundadırlar. Çalışanlar arasındaki cinsiyet, yaş, sağlık durumu, deneyim, engel hali gibi nedenlerden dolayı farklılıklar vardır. İşin düzenleniş şekli de, uygulanabilecek kuvvet veya momentin sınır değerini etkiler. Çalışanlardan uygulaması beklenen kuvvet ve momentleri belirleyebilmek için, birbirlerinden oldukça farklı, araştırma ve deneyim sonuçlarından yararlanılarak ortaya konmuş çok sayıda hesap yöntemi mevcuttur. Bu çalışmada, vakumlu sistemler ile yük kaldırma ve taşıma işinde çalışanın maruz kaldığı yük analiz edilmiştir. Çalışma şartlarında 9 ile 25 kg arasındaki kauçuk malzemeler, konteynerden vakumlu sistem ile alınarak konveyör banta bırakılmaktadır. Bu iş için görevlendirilen iş̧̧i, büyüklük ve ağılıkları değişen yaklaşık 150 adet kauçuk malzemenin yer değiştirme işlemini her gün düzenli olarak yapmaktadır. Vakumlu sistemler ile yük kaldırma ve yer değiştirme çalışma şartlarının, Federal Almanya Iş̧ Güvenliği ve İş Hekimliği Kurumunun Değerlendirme Yöntemi ve REBA Yöntemi ile analizi ve ergonomik risk değerlendirmesi yapılmıştır. Yapılan çalışma ile sağlık yönetimi alanında kas-iskelet sistemi hastalıklarının azaltılmasına katkıda bulunulmuştur.

Anahtar Kelimeler: Sağlık yönetimi, ergonomi, Federal Almanya iş güvenliği ve iş hekimliği kurumunun değerlendirme yöntemi, REBA Yöntemi

JEL Kodları: 110, L62 


\section{GiRiş}

Teknolojik gelişmeler sonucu otomasyona geçişe rağmen, işletmeler halen fiziksel insan gücüne ihtiyaç duymaktadır. Yoğun insan gücü kullanımı gerektiren işlerde uygun olmayan çalışma duruşları, kas iskelet sistemi rahatsızlıklarına neden olduğu gibi üretimin verimsizliğine de neden olmaktadır. Ergonominin temel amacı en fazla performansa en az insan gücü maliyetiyle (stres, zorlanma, yorgunluk, kazalar) ulaşmak olduğuna göre, hem işletme açısından hem de çalışan açısından önemli bir konu olan çalışma duruşlarının incelenmesi ve değerlendirilmesi de ergonomi içerisinde önemli bir yer tutmaktadır. Ergonominin amaçlarından biri de çalışma duruşlarının iyileştirilmesiyle, çalışanın yetenekleri ve iş gerekleri arasındaki dengenin oluşturulması ve sonucunda iş sağlığı ve güvenliği ve sistemin toplam verimliliğinin iyileştirilmesinin sağlanmasıdır (Akay vd 2003).

Kas iskelet sistemi rahatsılıklarının önlenmesi amacıyla iş yerlerinde ergonomik risk değerlendirmesi yöntemleri yapılmakta ve yapılan düzenlemelerle iş yükü hafifletilmektedir. Bu çalışmada, sıklıkla tekrarlanan statik ve dinamik duruşlara ve üst ekstremite pozisyonlarına göre seçilen REBA yöntemine yer verilmiş ve vakumlu sistemler ile yük kaldırma ve taşıma işinde çalışanın maruz kaldığı ergonomik risk değerlendirilmiştir.

\section{METOT}

Çalışma şartları analizinin yapıldığı firmada, 9 ile $25 \mathrm{~kg}$. arasındaki kauçuk malzemeler, konteynerden vakumlu sistem ile alınarak konveyör banta bırakılmaktadır. Bu iş için görevlendirilen çalışan, büyüklük ve ağırlıkları değişen yaklaşık 150 adet kauçuk malzemenin yer değiştirme işlemini her gün düzenli olarak yapmaktadır.

Uygun olmayan çalışma duruşu, vücut eklemlerinin normal duruşundan anlamlı düzeyde bir sapma olarak tanımlanmakta, kas ve iskelet sistemi rahatsızlıklarının önemli nedenlerinden biri olarak görülmektedir. Çalışma duruşlarının analizi sonucunda elde edilen sonuçlar genellikle yüksek risk taşıyan işlerin belirlenmesinde ve risklerin azaltılması amacıyla gerekli düzeltici faaliyetlerin başlatılmasında kullanılmaktadır (Kara vd 2014).

\subsection{Federal Almanya İş Güvenliği ve İş Hekimliği Kurumunun Değerlendirme Yöntemi}

Federal Almanya İş Güvenliği ve İş Hekimliği Kurumunun değerlendirme yöntemi ile, iş yerinde kaldırma, tutma, taşıma işlemleriyle, iterek veya çekerek yüke yer değiştirtme işlemlerinde işçinin ne kadar zorlandığını belirtmek mümkündür. İşçi için bir 'risk faktörü' hesaplanır ve temel özellikler olarak işin süresi, sıklığı, kaldırılan ve taşınan yükün beden konumu ve işin yapılış koşulları alınır. İşin özelliklerine göre verilen puanlar sonucu risk değeri olarak, yükü kaldırma, tutma ve taşıma işlerinde 2 ile 80 arası, yükü iterek veya çekerek yer değiştirme işlemlerinde de 3 ile 100 arası bir sonuç elde edilir. Matematiksel olarak 80'den büyük değer elde edilir ancak bu iş açısından olası değildir.

- $\quad$ Elde edilen sonuç değer 25'ten küçük ise işçi için risk söz konusu değildir.

- Sonuç 25 ile 50 arasındaysa çalışan zorlanma kapasitesine bağlı olarak bir risk ile karşı karşıya olabilir. Mutlaka işçinin işte ne kadar zorlandığı, her hangi bir sağlık problemi veya şikayeti olup olmadığı incelenmelidir.

- $\quad$ Eğer sonuç 50'den büyük ise önemli bir risk mevcuttur. Organizasyon veya teknik açıdan iyileştirme önlemleri alınarak risk faktörü mutlaka düşürülmelidir (Babalık, 2011).

Çalışmada analiz edilen duruşlar Şekil 1'de görüldüğü gibidir. Bu metotta gerçekleştirilen adımlar aşağıda verilmiştir. 


\section{Şekil 1: Çalışmada analiz edilen duruşlar}
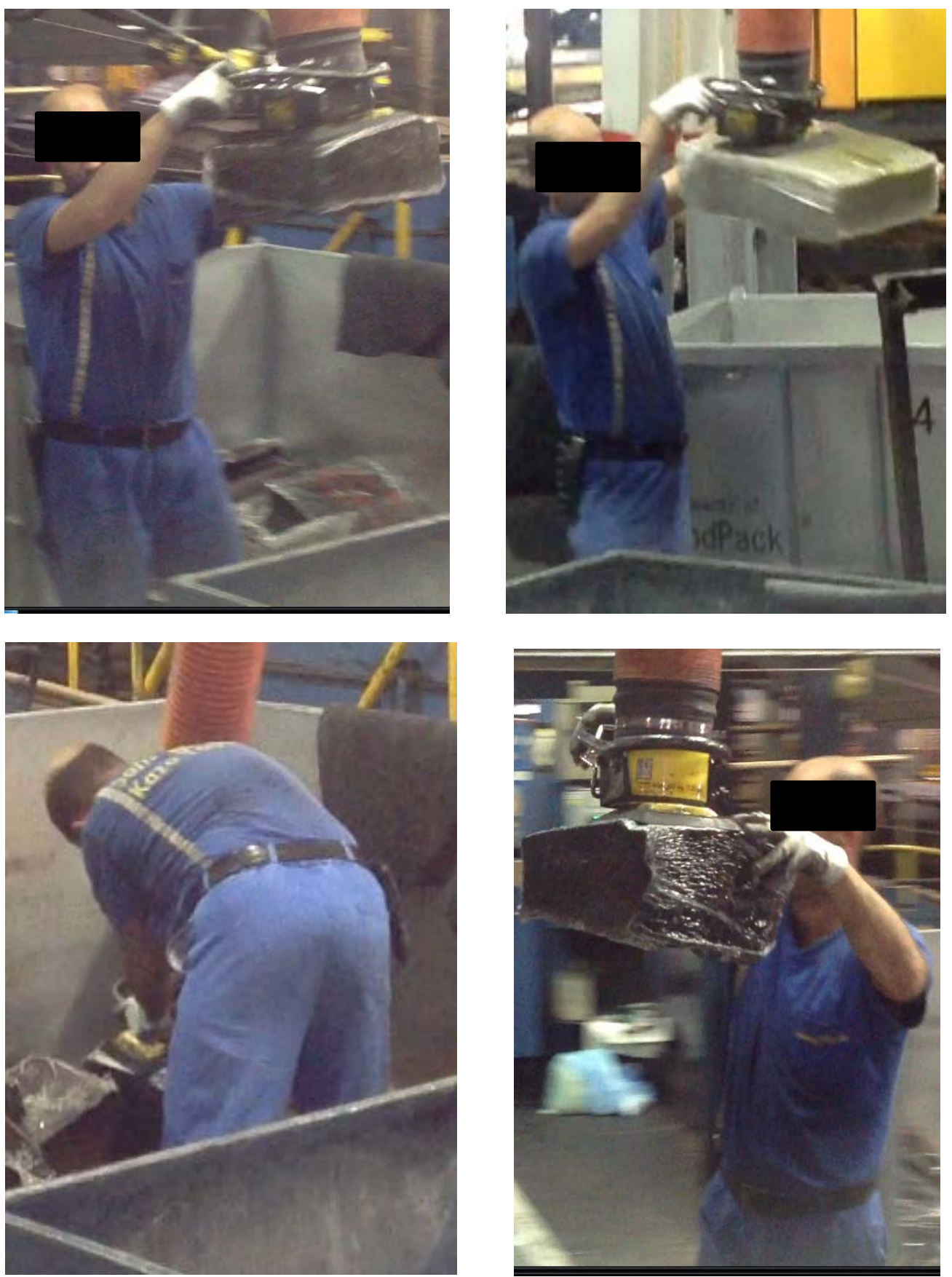

1.Adım: Zaman Ağırlığının Belirlenmesi. Öncelikle Tablo 1'de görüldüğü gibi iş süresi ve ağırlık derecesi belirlenir. Bir günde yapılan iş sayısı ortalama 150 olduğu için, zaman ağırlığı tabloda görüldüğü gibi 4 olarak seçilmiştir. 
Tablo 1: İş süresi ve ağırlık derecesi

\begin{tabular}{|c|c|c|c|c|c|}
\hline \multicolumn{2}{|c|}{$\begin{array}{l}\text { Kaldırma ve yer değiştirme } \\
\qquad(<5 \mathrm{~s})\end{array}$} & \multicolumn{2}{|c|}{$\begin{array}{l}\text { Tutma } \\
(>5 s)\end{array}$} & \multicolumn{2}{|c|}{$\begin{array}{l}\text { Taşıma } \\
(>5 \mathrm{~m})\end{array}$} \\
\hline $\begin{array}{l}\text { Bir günde } \\
\text { yapılan iş } \\
\text { sayısı }\end{array}$ & $\begin{array}{l}\text { Zaman } \\
\text { ağırlığı }\end{array}$ & $\begin{array}{l}\text { Bir günde } \\
\text { toplam } \\
\text { süre }\end{array}$ & $\begin{array}{l}\text { Zaman } \\
\text { ağırı̆ı̆ı }\end{array}$ & $\begin{array}{l}\text { Bir günde toplam } \\
\text { mesafe }\end{array}$ & Zaman ağırlığı \\
\hline$<10$ & 1 & $<5 \mathrm{dk}$ & 1 & $<300 m$ & 1 \\
\hline $10 \ldots .40$ & 2 & $5 \ldots .15 \mathrm{dk}$ & 2 & $300 \mathrm{~m} .1 \mathrm{~km}$ & 2 \\
\hline $40 \ldots . .200$ & 4 & $15 \mathrm{dk} \ldots 1 \mathrm{~s}$ & 4 & $1 \ldots 4 \mathrm{~km}$ & 4 \\
\hline $200 \ldots .500$ & 5 & $1 . . .2$ saat & 6 & $4 \ldots 8 \mathrm{~km}$ & 6 \\
\hline $500 \ldots 1000$ & 8 & 2.....4 saat & 8 & $8 \ldots .16$ km & 8 \\
\hline$\geq 1000$ & 10 & $\geq 4$ saat & 10 & $\geq 16 \mathrm{~km}$ & 10 \\
\hline
\end{tabular}

2.Adım: Yük, tutma ve uygulama şartlarının ağırlıklarının belirlenmesi. İşi yapan kişinin erkek ve etken kuvvetin 10 kg.'dan az olması sebebi ile, yük önemliliği Tablo 2'den 1 olarak seçilmiştir.

Tablo 2: Etken kuvvetler ve önemlilik derecesi

\begin{tabular}{|l|c|l|c|}
\hline $\begin{array}{l}\text { Etken kuvvet } \\
\text { (erkekler için) }\end{array}$ & $\begin{array}{c}\text { Yük } \\
\text { Onemliliği }\end{array}$ & $\begin{array}{l}\text { Etken kuvet } \\
\text { (kadınlar için) }\end{array}$ & $\begin{array}{c}\text { Yük } \\
\text { Önemliliği }\end{array}$ \\
\hline$<10 \mathrm{~kg}$ & $\mathbf{1}$ & $<5 \mathrm{~kg}$ & 1 \\
\hline $10 \ldots . .40 \mathrm{~kg}$ & 2 & $5 \ldots .10 \mathrm{~kg}$ & 2 \\
\hline $20 \ldots .30 \mathrm{~kg}$ & 4 & $10 \ldots .15 \mathrm{~kg}$ & 4 \\
\hline $30 \ldots . .40 \mathrm{~kg}$ & 7 & $15 \ldots .25 \mathrm{~kg}$ & 7 \\
\hline$\geq 40 \mathrm{~kg}$ & 25 & $\geq 25 \mathrm{~kg}$ & 25 \\
\hline
\end{tabular}

Çok hafif eğilme veya üst gövdenin döndürülmesi ve yük gövde yakınında olduğu için, konum ağırık derecesi Tablo 3'de görüldüğü gibi 2 olarak seçilmiştir. İyi ergonomik koşullar, yeterli alan, engelsiz çalışma alanı, düz kaymayan zemin, yeterli aydınlatma, tutabilme iyi ve kolay olduğu için, uygulama koşulları ağırlık derecesi Tablo 4'den 0 olarak seçilmiştir.

3. Adım: Değerlendirme Sonuç Tablosu. Bu adımda, daha önce bulunan yük önemliliği, konum ağırlığı ve uygulama şartları değerşeri toplanıp, zaman ağırlığı ile çarpılır.

$(1+2+0) \times 4=12$

Elde edilen değer risk tablosuna yerleştirilir (Tablo 5).

Tablo 5’e göre risk faktörü değeri 12 olduğu için, değerlendirme tablosundaki risk bölgesi 2 olarak seçilmiştir. Bu duruma göre, yük biraz fazla olduğu için çalışanın vücudunun zorlanması olasıdır. İş düzenlemesinde iyileştirme önlemleri anlamlı olur. 
Tablo 3: Konum ve ağırlık derecesi

\begin{tabular}{|c|c|c|}
\hline $\begin{array}{l}\text { Karekteristik Vücut } \\
\text { Konumları ve Yük } \\
\text { Pozisyonları }\end{array}$ & Vücut Duruşu, yükün pozisyonu & $\begin{array}{l}\text { Konum } \\
\text { ağırlığı }\end{array}$ \\
\hline & $\begin{array}{l}\text {-Gövdenin üstü dik, döndürülmüyor. } \\
\text {-Yük gövdede }\end{array}$ & 1 \\
\hline & $\begin{array}{l}\text { Çok hafif eğilme veya üst gövdenin döndürülmesi } \\
\text { Yük gövdede veya gövde yakınında. }\end{array}$ & 2 \\
\hline & $\begin{array}{l}\text { Aşağıya veya öne fazla eğilme } \\
\text { Öne eğilirken gövdenin üst kısmının döndürülmesi } \\
\text { Yük gövdeden uzakta veya omuz yüksekliğinden ileride }\end{array}$ & 4 \\
\hline & $\begin{array}{l}\text { Öne doğru fazla eğilirken aynı zamanda gövdenin üst } \\
\text { kısmının döndürülmesi. } \\
\text { - } \quad \text { Yük gövdeden uzakta } \\
\text { - } \quad \text { Ayakta konumunu sabit tutabilmek zor. } \\
\text { - } \quad \text { Çömelme veya diz üzerine çökme. }\end{array}$ & 8 \\
\hline
\end{tabular}

Tablo 4: Uygulama koşulları ve ağırlık derecesi

\begin{tabular}{|l|c|}
\hline Uygulama Koşulları & Uygulama Ağırlığı \\
\hline $\begin{array}{l}\text { İyi ergonomik koşullar, örneğin yeterli alan, engelsiz çalışma alanı, } \\
\text { düz-kaymayan zemin, yeterli aydınlatma, tutabilme iyi ve kolay }\end{array}$ & 0 \\
\hline $\begin{array}{l}\text { Hareket etme olanağı sınırlı, ergonomik koşullar kötü Örnek, } \\
\begin{array}{l}\text { 1- alçak tavan ve } 1.5 \text { m2 den daha az çalışma alanı } \\
\text { 2- düz olmayan veya yumuşak zemin nedeniyle ayakta dururken } \\
\text { sendeleme, düşme olasılığı. }\end{array}\end{array}$ \\
\hline $\begin{array}{l}\text { Hareket etme serbestliği çok sınırlanmış, veya yükün ağırlık merkezinin } \\
\text { değişken olması }\end{array}$ & 2 \\
\hline
\end{tabular}


Tablo 5: Risk değerlendirme tablosu

\begin{tabular}{|c|c|l|}
\hline Risk Bölgesi & Risk Faktörü Değeri & Açıklama \\
\hline 1 & $<10$ & $\begin{array}{l}\text { Düşük yük, vücudun fazla yüklenmesi nedeniyle sağlığın } \\
\text { kaybedilmesi olası değil }\end{array}$ \\
\hline 2 & $\mathbf{1 0 - 2 5}$ & $\begin{array}{l}\text { Biraz fazla yük, az yüklenebilen personel için vücudun } \\
\text { fazla zorlanması olası Böyle personel için iş } \\
\text { düzenlemesinde iyileştirme önlemleri anlamlı olur }\end{array}$ \\
\hline 3 & $25-50$ & $\begin{array}{l}\text { Epey fazla yük, normal yüklenebilir kişiler için de } \\
\text { vücudun fazla zorlanması olası. İş düzenlemesini } \\
\text { iyileştirme yönüne gidilmeli }\end{array}$ \\
\hline 4 & $>50$ & $\begin{array}{l}\text { Çok fazla yük, vücudun fazla zorlanma yüklenme olasıllığı } \\
\text { çok yüksek. Iş düzenlemesinde iyileştirme önlemleri } \\
\text { almak şart }\end{array}$ \\
\hline
\end{tabular}

\subsection{Reba Yöntemi ile Analiz ve Ergonomik Risk Değerlendirmesi}

REBA vücudun tüm kısımlarının analiz edilmesine olanak tanıyan bir yöntemdir (Hignett ve McAtamney, 2000). Bir çalışma duruşu esnasında gövdede, boyunda, bacaklarda, üst kollarda, alt kollarda ve bileklerde ortaya çıkan fleksiyon (bükme), ekstansiyonlara (germe) ve bu duruşlar esnasında çalışanın maruz kaldığı yüklere bağlı olarak 1 - 15 arası skor belirlenir. Bir çalışma duruşunun REBA skoru belirlenirken vücudun üst kısımları A ve B grubu diye ikiye ayrılır:

A Grubu: Gövde, boyun ve bacaklar (Tablo A)

B Grubu: Üst kollar, alt kollar ve bilekler (Tablo B)

Tablo A' da belirlenen skorlara Yük/Kuvvet skoru eklenerek A skoru, Tablo B' de belirlenen skorlara Kavrama skoru eklenerek B skoru elde edilir. Sonrasında Tablo C kullanılarak, A ve B skorlarının kombinasyonlarından oluşan C skoru elde edilir. C skoruna Aktivite skorunun ilave edilmesiyle REBA skoru elde edilmiş olur.

Tablo 6'dan gövde skoru $4(3+1)$ olarak belirlenmiştir.

Tablo 6: Gövde skoru

\begin{tabular}{|c|c|c|}
\hline Hareket & Skor & Skor değişimi \\
\hline Dik & 1 & \multirow{4}{*}{$\begin{array}{l}\text { Yana esneme veya dönme varsa } \\
+1\end{array}$} \\
\hline $\begin{array}{l}0^{\circ}-20^{\circ} \text { Fleksiyon (germe) } \\
0^{\circ}-20^{\circ} \text { ekstansiyon(bükme) }\end{array}$ & 2 & \\
\hline $\begin{array}{l}20^{\circ}-60^{\circ} \text { fleksiyon } \\
>20^{\circ} \text { ekstansiyon }\end{array}$ & 3 & \\
\hline$>60^{\circ}$ fleksiyon & 4 & \\
\hline
\end{tabular}

Tablo 7'den boyun skoru 1 olarak belirlenmiştir. 
Tablo 7: Boyun skoru

\begin{tabular}{|l|c|l|}
\hline Hareket & Skor & Skor değişimi \\
\hline $0^{\circ}-20^{\circ}$ fleksiyon & 1 & \multirow{2}{*}{ Yana esneme veya dönme varsa +1} \\
\cline { 1 - 2 } $\begin{array}{l}>20^{\circ} \text { fleksiyon veya } \\
\text { ekstensiyon }\end{array}$ & 2 & \\
\hline
\end{tabular}

Tablo 8'den bacak skoru 1 olarak belirlenmiştir.

Tablo 8: Bacak skoru

\begin{tabular}{|c|c|c|}
\hline Hareket & Skor & Skor değişimi \\
\hline $\begin{array}{l}\text { Bilateral (iki taraflı) ağırlık taşıma, } \\
\text { yürüme veya oturma }\end{array}$ & 1 & \multirow{2}{*}{$\begin{array}{l}\text { Dizlerde } 30^{\circ}-60^{\circ} \text { arası fleksiyon }+1 \\
\text { Dizlerde }>60^{\circ} \text { fleksiyon ( oturma hariç) } \\
+2\end{array}$} \\
\hline $\begin{array}{l}\text { Unilateral ( tek taraflı) ağırlık taşıma } \\
\text { veya sabit olmayan duruş }\end{array}$ & 2 & \\
\hline
\end{tabular}

A tablosundan, boyun skoru 1, bacak skoru 1 ve gövde skoru 4'e karşılık gelecek şekilde 3 skoru bulunur. EElde edilen değerler Tablo 9'da görülen A tablosuna yerleştirilir ve boyun skoru 1, bacak skoru 1 ve gövde skoru 4'e karşılık gelecek şekilde A tablosundan 3değeri okunur. A tablosu ile belirlenen bu skora Tablo 10'da görülen yük/kuvvet skoru eklenerek $A$ skoru elde edilir. Elde edilen değerlere göre $A$ skoru 3 olarak belirlenmiştir.

Tablo 9: A Tablosu

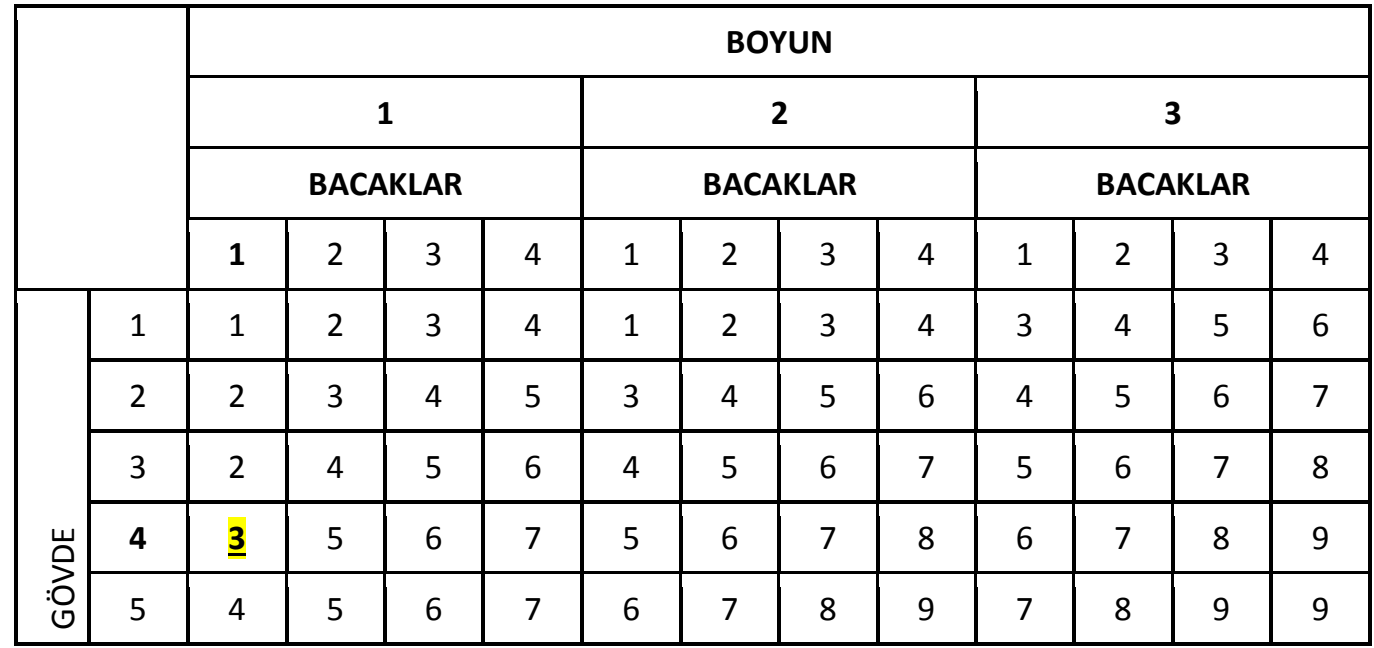


Tablo 10: Yük/kuvvet skoru

\begin{tabular}{|l|c|}
\hline Yük/kuvvet & Skor \\
\hline$<5$ kg & 0 \\
\hline $5-10 \mathrm{~kg}$ & 1 \\
\hline$>10 \mathrm{~kg}$ & 2 \\
\hline Ani veya hızlı kuvvet artışı & +1 \\
\hline
\end{tabular}

Tablo 11'den üst kol skoru 5 (4+1) olarak belirlenmiştir. Tablo 12'den Alt kol skoru 1 olarak belirlenmiştir. Tablo 13'den bilek skoru 1 olarak belirlenmiştir.

Tablo 11: Üst kollar

\begin{tabular}{|c|c|c|}
\hline Hareket & Skor & Skor değişimi \\
\hline $20^{\circ}$ fleksiyon $-20^{\circ}$ ekstansiyon & 1 & \multirow{4}{*}{$\begin{array}{l}\text { Kolda: } \\
\text {-Abdüksiyon varsa } \\
\text {-Rotasyon varsa }+1 \\
\text {-Omuz yükselmişse }+1 \\
\text {-Kolun duruşunda yerçekimi desteği } \\
\text { etkili ise }+1\end{array}$} \\
\hline $20^{\circ}-45$ fleksiyon $>20^{\circ}$ ekstansiyon & 2 & \\
\hline $45-90^{\circ}$ fleksiyon & 3 & \\
\hline$>90^{\circ}$ fleksiyon & 4 & \\
\hline
\end{tabular}

Tablo 12: Alt kol skoru

\begin{tabular}{|l|c|}
\hline Hareket & Skor \\
\hline $60^{\circ}-100^{\circ}$ Fleksiyon & 1 \\
\hline$<60^{\circ}-100^{\circ}$ fleksiyon veya $>100^{\circ}$ fleksiyon & 2 \\
\hline
\end{tabular}

Tablo 13: Bilek skoru

\begin{tabular}{|l|c|l|}
\hline Hareket & Skor & Skor değişimi \\
\hline $0^{\circ}-15^{\circ}$ fleksiyon veya ekstensiyon & 1 & Bileklerde yana esneme veya \\
\cline { 1 - 2 }$>15^{\circ}$ fleksiyon veya ektensiyon & 2 & \\
\hline
\end{tabular}

Elde edilen değerler B tablosuna yerleştirilir. Tablo 14'de görülen B tablosundan, alt kol skoru 1, bilek skoru 1 ve üst kol skoru 5'e karşılık gelecek şekilde 6 değeri bulunur. B tablosu ile belirlenen bu skora Tablo 15'de görülen kavrama skoru eklenerek B skoru elde edilir. Kavrama skoru olarak 0 değeri belirlenmiştir. Buradan B skoru = 6 +0 = 6 olarak elde edilir. Tablo 16'da görülen $C$ tablosundan A skoru ve B skoruna karşılık gelen değerler kesiştirilerek C skoru elde edilir. C tablosundan, A skoru 3 ve B skoru 6’ya karşılık gelecek şekilde 5 skoru bulunur. 
Tablo 14: B tablosu

\begin{tabular}{|c|c|c|c|c|c|c|c|}
\hline & & \multicolumn{6}{|c|}{ ALT KOL } \\
\hline & & \multicolumn{3}{|c|}{1} & \multicolumn{3}{|c|}{2} \\
\hline & & \multicolumn{3}{|c|}{ BILEK } & \multicolumn{3}{|c|}{ BILEK } \\
\hline & & 1 & 2 & 3 & 1 & 2 & 3 \\
\hline \multirow{6}{*}{$\begin{array}{l}\overrightarrow{0} \\
\text { - } \\
\stackrel{5}{\supset}\end{array}$} & 1 & 1 & 2 & 2 & 1 & 2 & 3 \\
\hline & 2 & 1 & 2 & 3 & 2 & 3 & 4 \\
\hline & 3 & 3 & 4 & 5 & 4 & 5 & 5 \\
\hline & 4 & 4 & 5 & 5 & 5 & 6 & 7 \\
\hline & 5 & $\underline{6}$ & 7 & 8 & 7 & 8 & 8 \\
\hline & 6 & 7 & 8 & 8 & 8 & 9 & 9 \\
\hline
\end{tabular}

Tablo 15: Kavrama skoru

\begin{tabular}{|l|l|c|}
\hline Derece & Açıklama & Skor \\
\hline İyi & İyi bir tutma kolu ve orta şiddette kavrama gücü & 0 \\
\hline Uygun & $\begin{array}{l}\text { El tutuşu uygun fakat ideal değil veya vücudun başka bir } \\
\text { bölgesi ile kavrama uygun }\end{array}$ & 1 \\
\hline Kötü & El tutuşu uygun olmamasına rağmen mümkün & 2 \\
\hline Uygun değil & $\begin{array}{l}\text { Zor ve güvenli olmayan tutuş, tutma kolu yok } \\
\text { Vücudun başka bir bölgesi kullanılarak tutuş uygun değil }\end{array}$ & 3 \\
\hline
\end{tabular}

Tablo 16: C tablosu

\begin{tabular}{|c|c|c|c|c|c|c|c|c|c|c|c|c|c|}
\hline & \multicolumn{12}{|c|}{ B SKORU } \\
\hline & & 1 & 2 & 3 & 4 & 5 & 6 & 7 & 8 & 9 & 10 & 11 & 12 \\
\hline \multirow{12}{*}{ 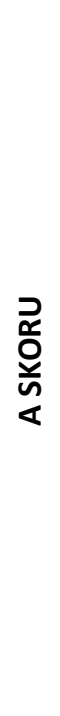 } & 1 & 1 & 1 & 1 & 2 & 3 & 3 & 4 & 5 & 6 & 7 & 7 & 7 \\
\hline & 2 & 1 & 2 & 2 & 3 & 4 & 4 & 5 & 6 & 6 & 7 & 7 & 8 \\
\hline & 3 & 2 & 3 & 3 & 3 & 4 & $\underline{5}$ & 6 & 7 & 7 & 8 & 8 & 8 \\
\hline & 4 & 3 & 4 & 4 & 4 & 5 & 6 & 7 & 8 & 8 & 9 & 9 & 9 \\
\hline & 5 & 4 & 4 & 4 & 5 & 6 & 7 & 8 & 8 & 9 & 9 & 9 & 9 \\
\hline & 6 & 6 & 6 & 6 & 7 & 8 & 8 & 9 & 9 & 10 & 10 & 10 & 10 \\
\hline & 7 & 7 & 7 & 7 & 8 & 9 & 9 & 9 & 10 & 10 & 11 & 11 & 11 \\
\hline & 8 & 8 & 8 & 8 & 9 & 10 & 10 & 10 & 10 & 10 & 11 & 11 & 11 \\
\hline & 9 & 9 & 9 & 9 & 10 & 10 & 10 & 11 & 11 & 11 & 12 & 12 & 12 \\
\hline & 10 & 10 & 10 & 10 & 11 & 11 & 11 & 11 & 12 & 12 & 12 & 12 & 12 \\
\hline & 11 & 11 & 11 & 11 & 11 & 12 & 12 & 12 & 12 & 12 & 12 & 12 & 12 \\
\hline & 12 & 12 & 12 & 12 & 12 & 12 & 12 & 12 & 12 & 12 & 12 & 12 & 12 \\
\hline
\end{tabular}


C tablosu ile belirlenen bu skora Tablo 17'de görülen aktivite skoru eklenerek REBA skoru elde edilir. Aktivite skoru +1 olarak belirlenmiştir.

Tablo 17: Aktivite skoru

\begin{tabular}{|l|c|}
\hline Aktivite & Skor \\
\hline $\begin{array}{l}\text { Bir veya daha fazla vücut bölgesi sabit } \\
\text { (örn: } 1 \text { dakikadan uzun süre tutma ) }\end{array}$ & +1 \\
\hline $\begin{array}{l}\text { Kısa aralıklarla tekrar eden işler } \\
\text { (örn: } 1 \text { dakikada 4' ten fazla tekrar eden iş ) ( yürüme hariç) }\end{array}$ & +1 \\
\hline $\begin{array}{l}\text { Yapılan iş duruşta hızlı ve büyük değişikliğe neden oluyorsa } \\
\text { veya sabit olmayan zeminde çalışılıyorsa }\end{array}$ & +1 \\
\hline
\end{tabular}

Sonuç olarak REBA skoru $5+1=6$ olarak elde edilmiştir. Tablo 18'e göre, REBA skoru 6 olduğu için, risk derecelendirmesindeki puanı 2 , risk seviyesi orta olarak bulunmuştur.

Tablo 18: REBA risk derecelendirme tablosu

\begin{tabular}{|c|c|c|c|}
\hline Derece & Reba skoru & Risk seviyesi & Önlem \\
\hline 0 & 1 & ihmal Edilebilir & Gerekli Değil \\
\hline 1 & $2-3$ & Düşük & Gerekli Olabilir \\
\hline $\mathbf{2}$ & $\mathbf{4 - 7}$ & Orta & Gerekli \\
\hline 3 & $8-10$ & Yüksek & Kısa Zaman İçerisinde Gerekli \\
\hline 4 & $11-15$ & Çok Yüksek & Hemen Gerekli \\
\hline
\end{tabular}

Yük biraz fazla olduğu için çalışanın vücudunun zorlanması olasıdır. İş düzenlemesinde iyileştirme önlemleri gereklidir.

\section{SONUÇ}

Vakumlu kaldırma ve iletme sistemleri çalışanların elleri ve beden güçleri ile yaptığı, nispeten hafif yüklerin taşınmasına yönelik çözümler sunmaktadır. Çalışanın kol, omuz, sırt, bel ve dizlerine binen yükleri ortadan kaldırıp, beden sağlığını korumasına yardımcı olur. Her iki yöntemde de görüldüğü gibi çalışanın vücuduna orta derecede bir yük binmektedir. Risk seviyesini artıran etmen, çalışanın yükü omuz seviyesinin yukarısında taşımasıdır. Rahat ve ergonomik bir kullanım için her bir çalışan için kaldırma yüksekliği değiştirilmelidir. Kaldırma körüğünün omuz seviyesinin altına indirilmesi ile çalışan vücuduna daha az bir yük binecek ve risk seviyesi düşecektir.

\section{KAYNAKLAR}

Akay D,Dağdeviren M ve Kurt M. Çalışma Duruşlarının Ergonomik Analizi. Gazi Üni. Müh.-Mimarlık Fakültesi Dergisi 2003; 18(3): 73-84.

Babalık, F.C. (2011), Mühendisler için Ergonomi - İşbilim, Dora Yayınclık, Bursa.

Hignett, S., McAtamney, L., 2000. Rapid Entire Body Assessment (REBA). Applied Ergonomics. 31, 201-205.

Kara Y, Atasagun Y, Peker, A (2014), Montaj hatlarında çalışma duruşlarının REBA yöntemi ile analizi ve ergonomik risk değerlendirmesi, VII. Uluslararası İş Sağığı ve Güvenliği Konferansı, 5-7 Mayıs 2014, İstanbul. 